\title{
STRATEGI PENINGKATAN KWALITAS PEMBERANGKATAN PEKERJA MIGRAN INDONESIA (PMI)
}

\author{
Wahid Erawan \\ Universitas Garut \\ wahiderawan@gmail.com
}

Received: December, 2020; Accepted: January, 2021

\begin{abstract}
This paper is the result of a literature study which is expected to be of benefit to academics, both students and lecturers, and it is also hoped that the relevant agencies can improve the quality of the departure of Indonesian migrant workers. Sometimes we neglect our duties and responsibilities, one of which is not paying attention to PMI's skills / expertise and only pursuing quota fulfillment targets. So that we need a good planning model between PMI, and a training place to improve the quality of PMI shipments in order to reduce PMI problems abroad. From the various existing literature, mapping strategies to improve the quality of migrant workers must follow the existing rules. From here it is not uncommon for the government, the private sector, or related agencies to encounter obstacles. In this study, the approach used is a qualitative approach, especially by using a systematic procedure for reviewing or assessing documents. The skills / expertise of prospective PMI need to be improved and supervision from the relevant government. In the future, we need a good planning model for training places to improve the quality of PMI shipments in order to reduce PMI problems abroad.
\end{abstract}

Keywords: quality, departure, and migrants

\begin{abstract}
Abstrak
Karya tulis ini merupakan hasil studi literatur yang diharapkan bermanfaat bagi kaum akademisi baik mahasiswa maupun dosen dan diharapkan pula bagi instansi yang terkait bagaimana strategi peningkatan kwalitas pemberangkatan pekerja migran indonesia. Kadang kita melalaikan tugas dan tanggungjawa, salah satunya tidak memperhatikan ketrampilan/keahlian PMI dan hanya lebih mengejar target pemenuhan kuota. Sehingga diperlukan sebuah model perencanaan yang baik antara PMI, dan tempat pelatihan untuk meningkatkan kualitas pengiriman PMI agar dapat mengurangi permasalahan PMI diluar negeri. Dari berbagai literatur yang ada, pemetaan strategi untuk meningkatkan kualitas pekerja migran harus mengikuti aturan-aturan yang ada. Dari sini tidak jarang pemerintah, pihak swasta , atau para instansi terkait menemui kendala. Pada penelitian ini, pendekatan yang digunakan adalah pendekatan kualitatif, terutama dengan menggunakan suatu prosedur sistematis untuk menelaah atau menilai dokumen- dokumen. Ketrampilan/Keahlian Calon PMI Perlu ditingkatkan dan pengawasan dari pemerintah yang terkait. Kedepan diperlukannya sebuah model perencanaan yang baik tempat pelatihan untuk meningkatkan kualitas pengiriman PMI agar dapat mengurangi permasalahan PMI diluar negeri.
\end{abstract}

Kata Kunci: kwalitas, pemberangkatan, dan migran

How to Cite: Erawan, W. (2021). Strategi Peningkatan Kwalitas Pemberangkatan Pekerja Migran Indonesia (PMI). Comm-Edu (Community Education Journal) 4 (1), 29-37.

\section{PENDAHULUAN}

Indonesia merupakan salahsatu negara pengirim tenaga kerja terbesar di dunia. Sebagian besar tenaga kerja yang berasal dari Indonesia bekerja di sektor informal, yang terbatas pada pekerjaan yang kotor, sulit dan berbahaya. Tenaga kerja yang bekerja disektor informal akan 
selalu menimbulkan masalah seperti penyiksaan, perlindungan, penganiayaan dan lainnya. Juga dalam hal pemberian perlindungan akan lebih sulit bagi tenaga kerja Indonesia yang masuk ke negara lain secara tidak resmi atau illegal. (Simanjuntak, Payman J, 2004).

Untuk perencanaan pekerjaan ke luar negeri sangat dibutuhkan pematangan program yang akan dilakukan. Hal ini pemerintah mensosialiasikan terhadap calon PMI dapat memasuki sektor kerja formal. Karena bekerja pada sektor formal akan terlindungi, bekerja ditempat yang ramai seperti di perusahaan dan pabrik, tetapi di sektor informal hanya berdua saja yaitu pekerja dan majikan (Febriani, 2008).

Hasil penelitian juga menunjukkan bahwa terdapat pengaruh positif antara pelatihan pra pemberangkatan terhadap stres akulturasi yang dimoderasi oleh sumber daya pribadi. Ini menunjukkan bahwa sumber daya pribadi memperkuat pengaruh pelatihan pra-keberangkatan terhadap stres akulturasi. Semakin tinggi sumber daya pribadi yang dimiliki oleh pekerja migran maka semakin kuat pengaruh pelatihan pra pemberangkatan terhadap stres akulturasi. Temuan ini mendukung pernyataan bahwa sumber daya pribadi merupakan salah satu indikator utama yang memengaruhi kinerja individu di tempat kerja. (Widayanti dan Sartika,2020)

Untuk itu kita harus lebih fokus dan selektif pengiriman PMI dalam penempatan, kualitas dan profesional di bidangnya sebelum dikirimkan keluar negeri. Kadang kita melalaikan tugas dan tanggungjawab. Salah satunya tidak memperhatikan ketrampilan/keahlian PMI dan hanya lebih mengejar target pemenuhan kuota.. Kedepan diperlukannya sebuah model perencanaan yang baik antara PMI, dan tempat pelatihan untuk meningkatkan kualitas pengiriman PMI agar dapat mengurangi permasalahan PMI diluar negeri.

\section{METODE}

Pada penelitian ini, pendekataan yang digunakan adalah pendekatan kualitatif. Penelitian dilakukan dengan melihat konteks permasalahan secara utuh dengan mengemukakan gambaran dan/atau pemahaman mengenai bagaimana dan mengapa suatu masalah selalu terjadi pada PMI. Pendekatan kualitatif yang digunakan dalam penelitian ini terutama dengan menggunakan studi dokumen atau lebih dikenal sebagai analisis dokumen sebagaimana diuraikan Bowen (Bowen, 2009), yaitu merupakan suatu prosedur sistematis untuk menelaah atau menilai dokumen- dokumen baik tercetak maupun elektronik, termasuk materi dari internet.

\section{HASIL DAN PEMBAHASAN}

\section{Karakteristik Calon PMI}

\section{Umur}

Ravenstein (1985) dalam "Hukum Migrasinya" menyatakan migrant biasanya adalah penduduk golongan muda/usia produktif. Pada usia ini mereka dianggap lebih mampu mengembangkan dan menyesuaikan diri dibandingkan dengan penduduk golongan tua (Nasution, 2001).

Kalau saja didalam negeri cukup tersedia lapangan pekerjaan bagi usia muda ini, maka mereka mampu meningkatkan perekonomian bangsa. Namun hal itu dimanfaatkan oleh pihak luar negeri sehingga ketika kembali kedalam negeri mereka sudah tidak produktif lagi. 


\section{Pendidikan}

Pendidikan yang diperoleh disekolah dan pelatihan ketrampilan adalah satu-satunya bentuk dari investasi modal yang dapat mempengaruhi penghasilan. Penghasilan akan meningkat setelah pendidikan selesai (lulus dari sekolah). Pendidikan formal biasanya selesai pada umur dua puluh lima tahun, namun penghasilan mungkin tetap konstan sepanjang kelompok umur tersebut, jika ingin menaikan produktivitas lulusan perguruan tinggi melalui investasi dalam pelatihan tempat kerja, meskipun profit tersebut meningkat melalui masa kerja. Hal ini dapat dilihat pada grafik 1 dibawah ini.

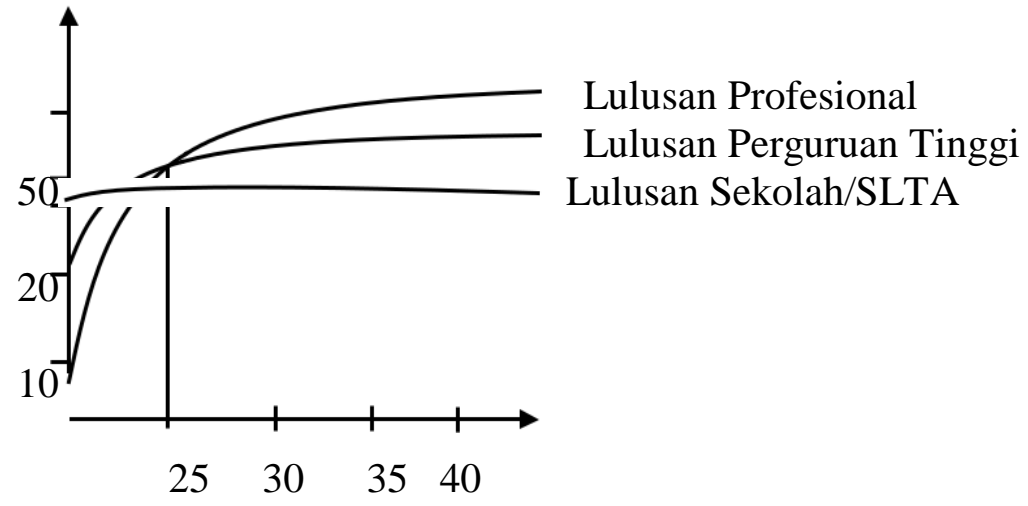

Gambar 1. Umur Sumber

Umur Sumber: (Dornbisch, 1987)

Pada grafik diatas memperlihatkan rata-rata penghasilan dengan lulusan sekolah, dimana pada tingkat lulusan sekolah/pendidikan yang rendah (lulusan SLTA kebawah) dan sedikit ketrampilan atau bahkan sama sekali tidak pernah mengikuti pelatihan ketrampilan akan memperoleh penghasilan yang rendah namun mereka menikmati hasil tersebut. Bagi lulusan perguruan tinggi, profit penghasilan yang diterima lebih banyak dari pada lulusan sekolah (SLTA kebawah). Sedangkan pada tingkat lulusan professional, yaitu mereka yang memiliki lebih tinggi pendidikan dan memperoleh pelatihan ketrampilan yang memadai akan memperoleh profit penghasilan yang lebih tajam dibandingkan dengan mereka yang lulus sekolah dan perguruan tinggi tetapi tidak/sedikit memperoleh pelatihan ketrampilan.( Febriani, 2011)

\section{Ekonomi}

Latar belakang kehidupan keluarga calon PMI lebih banyak dijadikan alasan untuk mengambil keputusan bekerja keluar negeri. Dari hasil wawancara dengan calon TKI dan survey yang dilakukan menyatakan menjadi PMI disebabkan karena latar belakang kehidupan ekonomi yang kurang, dan kalaupun mereka bekerja didaerah asal akan memperoleh pendapatan yang sangat kecil bahkan tidak mencukupi untuk memenuhi kebutuhan hidup sehari-hari. Kebanyakan orang tua responden memiliki pekerjaan sebagai petani 50,8 persen dan kalaupun ada yang pegawai negeri itu jumlahnya lebih sedikit yaitu sekitar 2,5 persen.

Kebanyakan pekerjaan calon PMI sebelum berangkat keluar negeri adalah penggangguran dan kalaupun ada yang bekerja hanya ber-dagang kecil-kecilan yang memiliki tingkat pen- 
dapatan antara Rp 200.000 - Rp 500.000/bulan, dan tidak mencukupi untuk memenuhi kebutuh-an mereka.

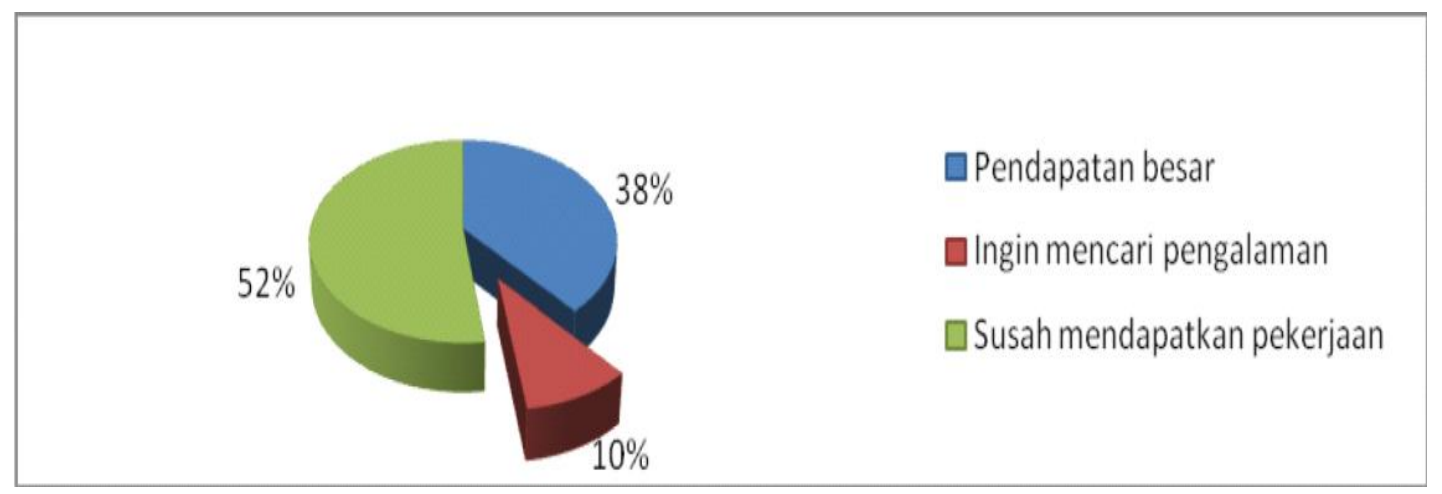

Gambar 2. Tujuan Bekerja ke Luar Negeri

Sumber: Data Lapangan Hasil Survey, Februari - Juli 2012

Dari grafik diatas terlihat bahwa pilihan bekerja keluar negeri dilakukan oleh PMI karena susah mendapatkan pekerjaan didalam negeri 52 persen jika dibandingkan dengan diluar negeri. Maka pilihan menjadi PMI merupakan keputusan akhir yang harus diambil agar bisa memperoleh pekerjaan dan penghasilan untuk memenuhi kebutuhan hidup. (Febriani, 2013)

\section{Hak dan Kewajiban}

Sebagai pekerja migran Indonesia tentunya mempunyai hak dan kewajiban yang diatur dalam ketentuan peraturan perundang-undangan sebagai bentuk pelindungan negara terhadap pekerja migran.

Hak dan kewajiban ini diatur dalam ketentuan Pasal 6 Undang-Undang Nomor 18 Tahun 2017 tentang Pelindungan Pekerja Migran Indonesia. Hak pekerja migran Indonesia terdiri dari: Hak sebagai calon pekerja migran Indonesia atau pekerja migran Indonesia dan Hak bagi keluarga pekerja migran Indonesia.

\section{Hak Calon/Pekerja Migran Indonesia}

Hak calon/pekerja migran Indonesia sebagaimana diatur dalam Pasal 6 ayat (1) UndangUndang Nomor 18 Tahun 2017 tentang Pelindungan Pekerja Migran Indonesia adalah:

- Mendapatkan pekerjaan di luar negeri dan memilih pekerjaan sesuai dengan kompetensinya.

- Memperoleh akses peningkatan kapasitas diri melalui pendidikan dan pelatihan kerja.

- Memperoleh informasi yang benar mengenai pasar kerja, tata cara penempatan, dan kondisi kerja di luar negeri.

- Memperoleh pelayanan yang profesional dan manusia serta perlakuan tanpa diskriminasi pada saat sebelum bekerja, selama bekerja, dan setelah bekerja.

- Menjalankan ibadah sesuai dengan agama dan keyakinan yang dianut.

- Memperoleh upah sesuai dengan standar upah yang berlaku di negara tujuan penempatan dan/atau kesepakatan kedua negara dan/atau perjanjian kerja.

- Memperoleh pelindungan dan bantuan hukum atas tindakan yang dapat merendahkan harkat dan martabat sesuai dengan ketentuan peraturan perundang-undangan di Indonesia dan di negara tujuan penempatan. 
- Memperoleh akses berkomunikasi.

- Menguasai dokumen perjalanan selama bekerja.

- Berserikat dan berkumpul di negara tujuan penempatan sesuai dengan ketentuan peraturan perundang-undangan yang berlaku di negara tujuan penempatan.

- Memperoleh jaminan pelindungan keselamatan dan keamanan kepulangan pekerja migran Indonesia ke daerah asal.

- Memperoleh dokumen dan perjanjian kerja calon pekerja migran Indonesia dan/atau pekerja migran Indonesia.

\section{Hak Bagi Keluarga Pekerja Migran Indonesia}

Hak bagi setiap keluarga pekerja migran Indonesia diatur dalam ketentuan Pasal 6 ayat (3) Undang-Undang Nomor 18 Tahun 2017 tentang Pelindungan Pekerja Migran Indonesia, yaitu:

- Mempeoleh informasi mengenai kondisi, masalah, dan kepulangan pekerja migran Indonesia.

- Menerima seluruh harta benda pekerja migran Indonesia yang meninggal di luar negeri.

- Memperoleh salinan dokumen dan perjanjian kerja calon pekerja migran Indonesia dan/atau pekerja migran Indonesia.

- Memperoleh akses berkomunikasi.

\section{Kewajiban Pekerja Migran Indonesia}

Kewajiban pekerja migran Indonesia diatur dalam ketentuan Pasal 6 ayat (2) Undang-Undang Nomor 18 Tahun 2017 tentang Pelindungan Pekerja Migran Indonesia, yaitu:

- Menaatai peraturan perundang-undangan, baik di dalam negeri maupun di negara tujuan penempatan.

- Menghormati adat istiadat atau kebiasaan yang berlaku di negara tujuan penempatan.

- Menaati dan melaksanakan perkerjaannya sesuai dengan perjanjian kerja.

- Melaporkan kedatangan, keberadaan, dan kepulangan pekerja migran Indonesia kepada perwakilan Republik Indonesia di negara tujuan penempatan.

Uraian di atas merupakan pengenalan awal mengenai pekerja migran Indonesia yang dapat menjadi acuan bagi para pencari kerja, perusahaan jasa tenaga kerja Indonesia, dan pemerintah dalam memberikan pelindungan kepada pekerja migran.

\section{Penanggulangan Kualitas Tenaga Kerja Indonesia yang Rendah}

Fakta di lapangan sering menunjukkan kepada kita bahwa kualitas tenaga kerja Indonesia harus ditingkatkan. Apalagi dalam menghadapi era globalisasi ekonomi dan perdagangan bebas yang memungkinkan masuknya tenaga-tenaga kerja asing ke tanah air, maka pemerintah dan masyarakat Indonesia mutlak harus meningkatkan kualitas tenaga kerjanya agar mampu bersaing dengan tenaga kerja luar negeri. Sebagai gambaran, saat ini kualitas tenaga kerja Indonesia yang bekerja di luar negeri masih dianggap lebih rendah dibanding kualitas tenaga kerja dari negara tetangga seperti Filipina. Dengan bukti bahwa tenaga kerja Filipina dihargai (dibayar) beberapa kali lipat lebih mahal dibanding tenaga kerja Indonesia. 
Oleh karena itu, sudah selayaknya bila pemerintah dan masyarakat berupaya untuk meningkatkan kualitas tenaga kerja.

Peningkatan kualitas tenaga kerja dapat dilakukan melalui:

- Jalur formal, seperti sekolah umum, sekolah kejuruan dan kursus-kursus.

- Jalur nonformal, yang terdiri atas:

- Latihan kerja, yaitu kegiatan untuk melatih tenaga kerja agar memiliki keahlian dan keterampilan di bidang tertentu sesuai tuntutan pekerjaan. Dalam hal ini Departemen Tenaga Kerja sudah mendirikan BLK (Balai Latihan Kerja) di setiap Daerah Tingkat II.

- Magang, yaitu latihan kerja yang dilakukan langsung di tempat kerja. Magang umumnya diselenggarakan oleh lembaga pendidikan yang bekerja sama dengan perusahaan-perusahaan yang dianggap tepat sebagai tempat latihan kerja. Tujuannya, setelah magang siswa menjadi tenaga kerja yang siap pakai. Kegiatan magang merupakan bagian dari proses Link and Match (Keterkaitan dan Kecocokan).

- Meningkatkan kualitas mental dan spiritual tenaga kerja. Untuk meningkatkan kualitas tenaga kerja, tidak hanya mengutamakan segi pengetahuan, keahlian dan keterampilan. Akan tetapi, kualitas mental dan spiritual seperti: keimanan, kejujuran, semangat kerja, kedisiplinan, terampil, inovatif, cerdas, bisa saling menghargai dan bertanggung jawab juga perlu ditingkatkan juga perlu ditingkatkan.

- Meningkatkan pemberian gizi dan kualitas kesehatan Tenaga kerja tidak mampu bekerja dengan baik bila kurang gizi dan kurang sehat. Kurang gizi bahkan bisa menurunkan kualitas otak (kecerdasan) yang justru sangat dibutuhkan dalam menyelesaikan suatu pekerjaan. Dengan demikian, peningkatan pemberian gizi dan kesehatan sangat dibutuhkan untuk meningkatkan kualitas tenaga kerja.

- Pengadaan seminar, workshop yang berkaitan dengan pekerjaan tertentu. (Evi Irviani, 2016)

\section{Ketrampilan/Keahlian Calon PMI}

Pemberian ketrampilan/keahlian kepada calon PMI sebelum berangkat keluar negeri penting dilakukan. Karena ketrampilan merupakan skill bagi tenaga kerja untuk mempercepat proses penyelesaian pekerjaan. Kita seharusnya sebelum memberangkatkan PMI keluar negeri terlebih dahulu harus memberikan pelatihan ketrampilan kepada calon PMI sesuai dengan pekerjaan yang ditekuninya diluar negeri agar tidak mengecewakan pihak penerima.

Kita khawatirkan jika tidak memberikan ketrampilan/ keahlian sebelum PMI diberangkatkan dan hanya mengandalkan ketrampilan yang diperoleh disaat sekolah saja. Hal ini tentu sangat kurang memenuhi keinginan pihak pengguna dalam penyelesain tugas yang diberikan. Untuk itu perlunya peningkatan lembaga tempat pelatihan/keahlian yang dikelola secara profesional dan diakreditasi oleh lembaga yang berwenang, dan tenaga kerja yang telah mengikuti pelatihan diberikan sertifikat yang diakui bukan saja didalam negeri tetapi juga negara lain.

Lembaga tempat pelatihan agar dapat menghasilkan lulusan yang berkualitas dan professional dalam bekerja harus memperhatikan antara lain: kualitas tenaga pelatih, pendidikan, kurikulum yang diberikan, ketersediaan dana, sarana dan prasarana yang dimiliki. Sehingga keahlian yang diberikan benar-benar bisa meme-nuhi kebutuhan pihak pengguna. 


\section{Pengembangan Sumber Belajar}

Buku Panduan yang berisi materi wawasan umum untuk PMI ini menggunakan prinsipprinsip teknologi pendidikan dan desain pesan dalam pengembangannya. Desain tersebut mengacu pada karakteristik PMI, karakteristik materi, dan hambatan. Karena karakteristik yang berbeda dengan kendala yang berbeda, menghendaki pendekatan yang berbeda pula (Miarso, 2004:540).

Prinsip dasar yang perlu dijadikan acuan dalam pengembangan dan pemanfaatannya, yaitu pendekatan sistem, berorientasi pada peserta didik dan pemanfaatan sumber belajar.

Prinsip pertama, pendekatan sistem yang berarti bahwa setiap usaha pemecahan masalah pendidikan, dilandasi konsep teknologi pembelajaran yang menerapkan prinsip pendekatan sistem. Artinya memandang segala sesuatu yang menyeluruh (komprehensif) dengan segala komponen yang saling terintegrasi. Pendekatan sistem dalam desain instruksional terdiri dari tiga tahap yaitu mengidentifikasi, mengembangkan, dan melakukan evaluasi formatif (Atwi Suparman, (2012:113). Pendekatan sistem ini digunakan dalam menerapkan, menganalisis, dan mengevaluasi proses diklat yang di laksanakan mengacu pada kebutuhan peserta didik dalam ini adalah pmi.

Prinsip kedua, adalah pembelajaran yang berorientasi pada peserta didik, prinsip berorientasi pada peserta didik berarti bahwa usaha-usaha pendidikan, pembelajaran, dan pelatihan hendaknya memusatkan perhatiannya pada peserta didik, dengan memperhatikan karakteristik, minat, potensi dari peserta didik dalam hal ini berorientasi pada PMI. Motivasi belajar merupakan satu faktor yang internal yang mempengaruhi prestasi belajar (Ismawardani, 150:2015) maka pada awal penelitian dilakukan need assesment untuk mengetahui sumber belajar yang dibutuhkan dan meningkatkan motivasi belajar sesuai karakteristik TKI sehingga hasil belajar meningkat.

Prinsip ketiga, memanfaatkan media atau sumber belajar. Pemanfaatan media dan sumber belajar semaksimal dan sevariatif mungkin, prinsip ini berarti bahwa peserta didik belajar karena berinteraksi dengan media atau sumber belajar secara maksimal dan bervariasi. Berdasarkan teori dalam ranah teknologi pendidikan, maka ada dua solusi yang dapat dilakukan dengan menyiapkan proses belajar atau mengembangkan suatu produk (sumber belajar) yang menarik.

Prinsip keempat, yaitu desain pesan, yang merupakan perencanaan untuk merekayasa bentuk pesan secara fisik. Menurut Fleming dan Levie prinsip tersebut mencakup prinsip perhatian, persepsi, dan daya serap yang mengatur penjabaran bentuk fisik dari pesan agar terjadi komunikasi antara pengirim dan penerima (Seels \& Richey, 1994) dalam Fatikhatun Najikah (2018)

\section{Pembekalan Akhir Pemberangkatan (PAP)}

Persiapan mental untuk bekerja ke luar negeri jangan disepelekan karena kita dituntut mampu mandiri di negeri orang. Sebelum berangkat ke luar negeri, perlu memberikan pembekalan akhir pemberangkatan (PAP) untuk memantapkan keinginan dan tekad PMI ke luar negeri. Program ini diwajibkan oleh pemerintah agar calon tenaga kerja yang dikirim mengetahui aturan-aturan yang ditetapkan oleh pihak perusahaan yang mempekerjakan mereka dan mengetahui gambaran bekerja diluar negeri. 
Program PAP ini harus melibatkan wakil-wakil semua instansi yang terlibat seperti pihak Disnakertrans, imigrasi, asuransi, dan ahli agama. Dalam pembekalan tersebut akan diketahui segala sesuatu yang berkaitan dengan hak dan kewajiban selama bekerja atau cara bekerja di luar negeri atau gambaran bekerja diluar negeri itu seperti apa serta hal lain yang berkaitan dengan mentalitas tenaga kerja.

Pembekalan Akhir Pemberangkatan (PAP) terhadap calon PMI meliputi:

a. Pembinaan mental kerohanian oleh pemuka agama.

b. Situasi dan kondisi kerja diluar negeri .

c. Budaya, adat-istiadat, dan hukum negara negara tujuan

d. Hak dan kewajiban bagi calon PMI.

e. Cara mengatasi permasalahan diluar negeri.

f. Tata cara perjalanan dan kepulangan PMI.

g. Program tabungan dan pengiriman uang bagi PMI.

h. Penjelasan kelengkapan dokumen yang ha-rus dibawa oleh PMI

\section{KESIMPULAN}

Melihat perkembangan teknologi dunia sangat cepat, penulis menyadari akan pentingnya strategi dalam mempersiapkan pemberangkatan Pekerja Migran Indonesia maka diperlukan.

1. Penanggulangan kualitas tenaga kerja Indonesia yang rendah bisa diambil secara sekolah formal dan nonformal.

2. Ketrampilan/Keahlian Calon PMI Perlu ditingkatkan dan pengawasan dari pemerintah yang terkait.

3. Pengembangan sumber belajar harus memperhatikan prinsip pendekatan sistem, pembelajaran yang berorientasi pada peserta didik dan memanfaatkan media atau sumber belajar.

4. Kedepan diperlukannya sebuah model perencanaan yang baik tempat pelatihan untuk meningkatkan kualitas pengiriman PMI agar dapat mengurangi permasalahan PMI diluar negeri.

\section{DAFTAR PUSTAKA}

Atwi Suparman. (2012). Desain Instruksional Modern. Jakarta: Erlangga.

Bowen, G.A, 2009. Media Analysis Techniques. Beverly Hiils: Sage Publications Darmanto, Wulan, 2019. Easy Writing - Teknik Menulis Ringan - Materi Temu Aksi Nasional Penyuluh Antikorupsi di ACLC KPK Jakarta pada pada 11-13 Desember 2019

Evi Iviani, (2016) Kualitas Tenaga Kerja Indonesia https://eviirviani.wordpress. com/2016/07/20/kualitas-tenaga-kerja-indonesia/

Fatikhatun Najikah (2018) Pengembangan Buku Panduan Sebagai Sumber Belajar Untuk Tenaga Kerja Indonesia file://C:/Users/acer\%20v5/ Downloads/

Documents/4766-15127-1-PB.pdf

Febriani, 2009 Pelayanan Sosial Bagi TKI Bermasalah Asal Sumatera Barat Jur. Normativ Vol 1 ed. 12 Fak. Hukum Univ. Tamansiswa Padang

Febriani, 2011 Peningkatan Kualitas Pendidikan Dan Ketarampian Tkimenuju Ketaraan Upah Di Lauar Negeri Sebuah Konstruksi. Jurnal Manaajemendan kewirausahaan Vol 2 No.1 Fak. Ekonomi Univ. Tamansiswa Padang 
Febriani dan Meita Lefi Kurnia, 2013 Perencanaan Bagi PJTKI Dan Lembaga Tempat Pelatihan Yang Berkualitas Untuk Mewujudkan Eksport Tenga Kerja Yang Profesioanal. Jurnal Manaajemen dan Bisnis Vol 17 No.1 Fak. Ekonomi Program Studi Manajemen Univ. Tamansiswa Padang

Ismawardani, N. (2015). Pengaruh Penggunaan Limbah Tapioka Sebagai Sumber Belajar Terhadap Motivasi Dan Hasil Belajar Siswa. Jurnal cakrawala pendidikan, februari 2015, th. Xxxiv, no. 1. E-ISSN: 2442-8620.

Miarso, Yusuf Hadi. (2004). Menyemai Benih Teknologi Pendidikan. Jakarta: Prenada Media.

Nasution, Arf, 2001, Orang Indonesia di Malaysia Menjual Kemiskinan Membangun Identitas, Yogyakarta, Pustaka Pelajar

Revenstein, E.G.1998. The Laws of Migration. Journal of the Statistical Society 48; 167-219

Simanjuntak, Payman J, 2004, Perlindungan Tenaga Kerja Ilegal di Malaysia, Jurnal Informasi Hukum, Vol.2 Tahun VI, 2004

Widayanti dan Sartika, 2020 Pre-Departure Training and Personal Resources: How it Affects Acculturative Stress? *, *Corresponding author i Volume 19 (1), 2020: 31 - 40 PISSN: 1412-8969; E-ISSN: 2461-0771 